\title{
A STUDY ON INTER-PARENTAL CONFLICT AND AGGRESSION AMONG UNIVERSITY STUDENTS
}

\author{
Naila Zaman \\ M.Phil. Scholar \\ Department of Psychology, University of Gujrat, \\ Punjab, Pakistan \\ Email: naila.zaman@gmail.com

\section{Dr. Noreena Kausar} \\ Assistant Professor, \\ Department of Psychology, University of Gujrat \\ Punjab, Pakistan \\ Email: noreena.kausar@uog.edu.pk \\ Mueen Abid \\ Ph.D. Scholar, \\ Department of Psychology, University of Gujrat, \\ Punjab, Pakistan \\ Email: mueen.abid.uog@gmail.com
}

\begin{abstract}
Parental conflicts have a great impact on the learning and behavior of students. Thus, the current study intended to explore the relationship between perceived inter-parental conflict and aggression among university students. To draw the sample of study stratified proportionate sampling method was applied and 316 university students (age range 17-23 years) were included in study. Children's Perceived Inter-parental Conflict Scale (age range 6-25 years) and Perry Aggression Questionnaire (age range 15-25years) were used to measure study variables. Data were examined by using descriptive statistics, correlation, regression analysis, t-test, and ANOVA. Findings highlighted that there is a significant positive correlation between perceived inertparental conflict and aggression among university students $(r=.397, p<0.05)$. Furthermore, regression analysis revealed a significant predictive relationship between inter-parental conflicts and aggression $\left(R^{2}=.15, F=57.88, p<0.001\right)$. Whereas, the results of $t$-test and ANOVA revealed that demographic features like gender, household type and living with genetic parents and step parents have no substantial role in inter-parental conflict and aggression.
\end{abstract}

KEYWORDS

Inter-parental conflict, Aggression, Regression, Biological parents 
INTRODUCTION

Family is a primary organization of a child where the child learns to think, perceive, explore and respond the world. As a child passes most of the time with his or her family members, especially parents. Parents play a vigorous part in shaping personality of child. Parent child bond has great influence on a child's psychological and physical fitness. Parents can contribute to their youngsters' progress and growth by fulfilling their basic and psychological needs, and by addressing and sharing their concerns which help them developing a constructive perspective (Repetti, Taylor, \& Seeman, 2002).

Parents are supposed to construct a firm basis for their children to promote their prosperous and satisfying life. It is essential to develop these basis at early stages of life especially and during childhood and adolescence. As, these phases of life required strong parental communication for healthy personality development. Parents have to share their feelings and thoughts with offspring and also involve them in family matters which provides a sense of belongingness and achievement. Children expression of feelings, thoughts and complications with parents is helpful to develop a stable personality. Along with parent's role home atmosphere is also very important in the life of child. Environment at home helps making child a well-adjusted, balanced and a peaceful, cooperative person or vice versa. Home atmosphere can be healthy or unhealthy (Mash \& Dozois, 2003).

Optimistic and firm relationship between parents stimulate pleasant and safe home environment deliver a sense of community incorporation and emotional safety which eventually allow teens to engage effective self-regulation. While, problematic and unsympathetic parental relationship leads to unhealthy home environment which has harmful effects on physical and psychological health of offspring. For instance, inappropriate familial association, less supportive and negligent parents, poor development, overt domestic clashes, recurrent occurrences of resentment and violence between parents make children susceptible to many psychological and physical health complications (Repetti, Taylor, \& Seeman, 2002).

Inconsistencies, opinions and debates on certain domestic issues are normal but sever and frequent discrepancies and conflicts of parents yield long term emotional clashes between parents. These inter-parental rattles have imperious impact on them and are somewhat which seriously disturb offspring's life. Findings identified that poor interparental behaviors and unresolved parental conflicts caused continuous aggression in children which further leads to poor educational performance (Mash \& Dozois, 2003).

\section{LITERATURE REVIEW}

Pakistani and international researchers conducted different studies to explore 
relationship between inter-parental conflicts and aggression, some of them are following:

A study was conducted by Bernet, Wamboldt and Narrow 2016, to explore interparental clashes and level of violence and aggression on their off springs. This study documented that conflicts between parents have a potential impact on youngsters' psychological fitness and advancement of life, with current amendments to clinical investigative outlines underlining the currently extensively recognized indication calling for larger medical gratitude of inter-parental skirmish as a primary reason of poor psychological health consequences for adolescence (Bernet, Wamboldt, \& Narrow 2016). Additionally, differentiating between positive and negative conflict between parents, their mismanagement plans may clarify why dissimilarities occur in youngsters' healthy and unhealthy reactions to conflicts between parents. Negative skirmish conducts such as viciousness, hostility, soundless conflicts and battles around children matters are related with amplified suffering or risk for mental regulation glitches in broods of all ages (Cummings \& Davies, 2002), with latest indication emphasizing intergenerational conduction of revelation to parental viciousness (Narayan, Labella, Englund, Carlson, \& Egeland, 2017). Nevertheless, afore this deduction can be assuredly recognized in relation to strategy and preparation endorsements, a practical trial comparative to the applied effectiveness of this confirmation base essential to be addressed firstly. So in the light of previous findings it is necessary to explore the effects of inter-parental conflicts and aggression among university students.

Buehler, Anthony, Krishnakumar, Stone, Gerard, and Pemberton (1997) pointed out that parental conflict may cause many internalizing and externalizing problems in children. Anxiety, hostility, depression refer to the internalizing problems, they are usually turned inward. Whereas, externalizing symptoms are turned outwardly, it included vocal and bodily aggression, devastation of property, crime, rebelliousness and theft etc. Aggression is an overt behavior which is intended to harm others. It is articulated in a variety of conducts such as abusive talk, physical injuries and destruction of respect or property (Franken, 2002). Figure 1 illustrating study model of inter-parental clashes at home elevated the likelihoods of being hostile in future life.

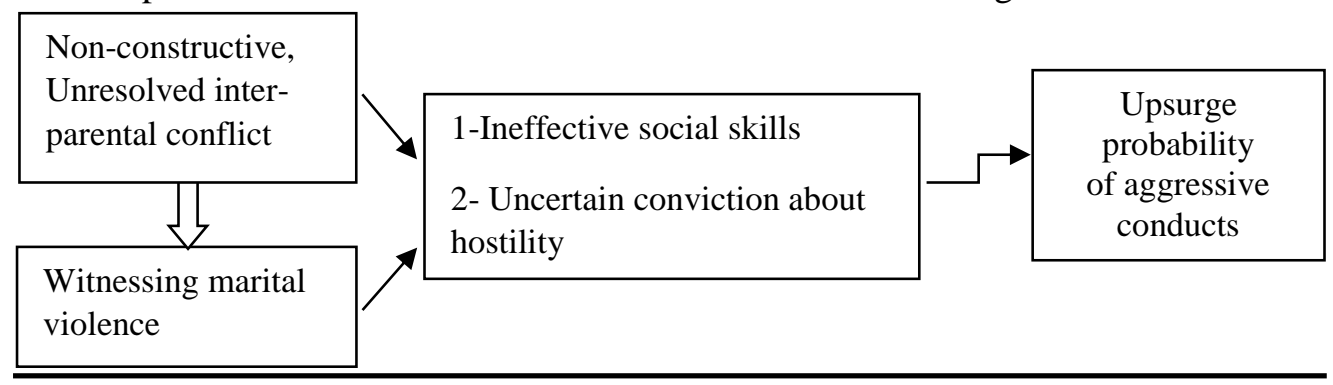


In the light of previous studies and recent research gap present study intended to measure relationship between perceived inter-parental conflict and aggression among university pupils and role of certain demographic variables with respect to biological parents and step parents.

\section{RESEARCH OBJECTIVE}

1. To explore relationship between inter-parental conflicts and aggression among university students.

2. To investigate the effects of demographic features in above said association.

\section{RESEARCH QUESTION}

1. Is there a relationship between inter-parental conflicts and aggression among university students?

\section{RESEARCH METHODOLOGY}

This study used correlational survey research design to examine study variables. It was conducted in University of Gujrat, Hafiz Hayat Campus. All the students from various department of social sciences were included in this study. Sample size of research was determined by using TaroYamane formula (Israel, 2013) and data were collected from $316(n=316)$ university students by using proportionate stratified random sampling. In which departments of social sciences were taken as strata's of the current study. Strata's were made at three steps. All departments of social sciences were taken at the first step, all semesters of BS Hons were selected on the second step, and at the third step gender based strata were made. Sampling frame was obtained from concerned head of departments. Depending on the proportion of students in each semester of a department, sample size was determined. Instruments of current study consist of three parts, in first part a self-constructed demographic form was used to acquire information about participant's gender, age, education, semester, department, family setup, living with genetic parents or step parents, parent's education, professions and living area. In second part, Children's Perception of Inter-parental Conflict Scale (Grych, Fincham \& Seid, 1992) was used to measure inter-parental conflicts. While in third part, in order to measure aggression adult version of Buss-Perry Aggression questionnaire (Buss \& Perry, 1992) was used.

In present study both scales presented high test-retest reliability and internal consistency (Inter-parental conflict scale $=0.85$, Aggression scale $=0.89$ ). Procedure applied in this study were sanctioned by the Advanced Studies and Research Board (ASRB), University of Gujrat, Pakistan. Before data collection a formal permission was taken from concerned authorities of department from where sample was to be drawn. Formal informed agreement was taken from respondents and they were informed about the aim of research, its implication and voluntary based participation. 
Confidentiality and privacy of data were ensured by researcher. Data were analyzed by using SPSS 20 version. Descriptive statistics, correlation, regression analysis, t-test and ANOVA were applied.

\section{RESEARCH FINDINGS}

Table 1

Pearson Correlation Analysis $(n=311)$

\begin{tabular}{lccc}
\hline Variables & Mean & Standard Deviation & $\boldsymbol{r}$ \\
\hline IPC & 86.78 & 13.97 & $.397^{* *}$
\end{tabular}

$\begin{array}{lll}\text { Aggression } \quad 84.42 & 16.45\end{array}$

Note. $* * P<0.01 ; d f=309$

IPC=Inter-parental conflict, AGG=Aggression

Table 1. Revealed the results of correlation analysis which depicted a strong momentous relationship between inter-parental and aggression $(r=.397, p<0.01)$. Moreover, results designated that level of aggression upsurge with high the level of inter-parental conflicts.

Table 2

Regression Analysis $(n=311)$.

\begin{tabular}{lccccc}
\hline Variables & Model 1 B & $\mathbf{R}^{2}$ & $\mathbf{F}$ & $\Delta \mathbf{R}^{2}$ & $\Delta \mathbf{F}$ \\
\hline $\begin{array}{l}\text { Aggression } \\
\text { Inter-parental }\end{array}$ & & & & & \\
Conflict & $.397^{* * *}$ & .155 & $57.88^{* * *}$ & .158 & $57.88^{* * * *}$ \\
& $(.000)$ & & $(.000)$ & & $(.000)$
\end{tabular}

Note. $* * * p<0.001$

Table 2. Specified that inter-parental conflict is a significant predictor of aggression among university students. As the value of $\mathrm{R}^{2}$ indicated that $15 \%$ of variation in aggression is due to inter-parental conflicts $(\mathrm{p}<.001)$.

Table 3

T-test analysis $(n=311)$.

Male $\quad$ Female $95 \% \mathrm{CI}$


PJER, Vol 3, Issue 2 (2020)

A study on...

\begin{tabular}{lccccccccc}
\hline \multicolumn{1}{|c}{ Variables } & M & SD & M & SD & $\begin{array}{c}\text { T } \\
\mathbf{( 3 0 9 )}\end{array}$ & Sig & LL & UL & $\begin{array}{c}\text { Cohe } \\
\text { n's d }\end{array}$ \\
\hline $\begin{array}{l}\text { Inter- } \\
\text { parental }\end{array}$ & 88.97 & 13.28 & 84.72 & 14.33 & 2.706 & 0.07 & 1.16 & 7.33 & 0.307 \\
$\begin{array}{l}\text { conflict } \\
\text { Aggression }\end{array}$ & 84.82 & 18.02 & 84.05 & 14.86 & .409 & 0.68 & -2.93 & 4.46 & 0.04 \\
\hline
\end{tabular}

Note. $C I=$ confidence interval; $L L=$ lower limit; $U L=$ upper limit.

Results of $t$-test demonstrations that there is no substantial gender alteration in interparental conflict and aggression as $t(309)=2.706, p>.05, t(309)=0.409, p>.05$.

Table 4

One way ANOVA analysis $(n=311)$

\begin{tabular}{ccccccccc}
\hline \multicolumn{9}{c}{ Real/genetic } \\
Parents & \multicolumn{9}{c}{ Step Parents } \\
Variable & $\boldsymbol{M}$ & $\boldsymbol{S D}$ & $\boldsymbol{M}$ & $\boldsymbol{S D}$ & $\boldsymbol{M}$ & $\boldsymbol{S D}$ & $\boldsymbol{F}$ & $\boldsymbol{p}$ - \\
s & & & & & & & & value \\
\hline IPC & 86.7 & 13.9 & 87.38 & 13.0 & 87.00 & 16.39 & .014 & .986 \\
AGG & 84.7 & 16.0 & 82.50 & 19.7 & 80.0 & 21.40 & .593 & .553 \\
\hline
\end{tabular}

Note. IPC=perceived inter-parental conflict; $\mathrm{AGG}=$ aggression

Table 5. One way ANOVA was applied to check mean difference of inter-parental conflict and aggression with respect to participant's biological and step parents. Findings displayed that there is insignificant difference in inter-parental conflict and aggression with respect to biological and step parents as the values $\mathrm{F}(2,308)=0.014$, $\mathrm{p}>.05, \mathrm{~F}(2,308)=0.593, \mathrm{p}>.05$ specified no statistical significant difference.

\section{CONCLUSION AND DISCUSSION}

The first objective was to investigate relationship between perceived inter-parental conflict and aggression. Outcomes of study presented strong positive relationship between above said constructs $(r=.397, p<0.01)$. It shows the increasing trend in Perceived inter-parental conflict and aggression.

Current findings are consistent in the streak of earlier studies, Marcus, Lindahl, and Malik (2001); McDonald and Grych (2006); Fosco and Grych (2008); \& Jamil and Mubashir (2012) originated statistical significant association between inter-parental conflicts and aggression. Conflicts between parents adversely affect overall home environment and childrearing skills and when children observe their parental conflicts they have risk to indulge in such type of negative behaviors in future. 
In Pakistan, some parents do not pay attention towards the emotional needs of their children. They are busy in earning more and more and have no time to sit with the family and discuss their concerns. In such home environment when parents have arguments, they do not like to explain themselves in front of their children, as find it embarrassing. Unknowingly they make their children detach from them. Children being helpless all the time absorb in negative activities and finally they do catharsis in form of anger either toward others or to themselves.

Second objective of current study was to identify predictive relationship between interparental conflict and aggression. Regression analysis was carried out to study this objective which exposed statistical significant predictive relationship between interparental conflict and aggression among university students $(p<.001)$.

Results of the study are consistent with earlier work. Litrownik, Newton, Hunter, Diana, and Everson (2003) and Nicholas and Rasmussen (2006) also found that IPC predict aggression. In Pakistani culture, there could be some familial and social factors which can play directly and indirectly role in developing or aggravating aggression among emerging adults. As now days almost all of the Pakistanis face political and social insecurities, many families may face financial issues which can trigger aggressive tendencies in emerging adults. Media and peer group also play an important role in increasing level of aggression in adults. Furthermore, in third objective of this study was to find out gender variance in relation to perceived inter-parental conflict and aggression. Results of t-test showed insignificant gender differences $(t(309)=$ $2.706, p>.05, \& t(309)=0.409, p>.05$ respectively). Results of the existing study are reliable with the results of following studies. As Davies and Lindsay (2004) established that gender does not show important role in perceived inter-parental conflicts and aggression among university students. It can be justified with the changing trends in society's attitude toward male and female children. Currently in most of the sub cultures of Pakistan, equal right movement is not only supporting but also practicing male female education and equal job opportunities as both genders have equal rights to move on. The study sample was taken from university which shows that they are in the phase of educating themselves and probably it is their educational environment which increases their awareness level in equal role participation.

Difference in experiencing inter-parental conflicts and aggression among participants in relation to their living with biological parents and step parents. Findings of one way ANOVA $(M=86.7,87.38,87.0$ respectively) depicted no statistic significant mean difference. These outcomes are in line of previous studies such as Davis, Hops, Alpert and Sheeber (1998); Orpinas, Murray and Kelder (1999); \& Jenkins, Simpson, Dunn, Rabash, and O'Connor, 2005). Further it can be the participant's maturity level which helps him to handle affairs effectively. Nature of relationship of parents with their 
children can also matters in developing aggression in adults. Now the changing trend in Pakistan make parents aware about the concerns of children. Now parents start taking their children in confidence and discuss issues with them. Some parents have marital conflicts with each other but their relationship with children is smooth so their conflicts cannot directly influence on the behavior of adults.

At the end, these findings would be useful for parents to understand adverse effects of their clashes on their children. It also helps students to control their aggressive tendencies. The study would help the university administration to conduct such seminars which can teach the constructive way of expression of emotions to the students.

Current study concluded that parents should not involve themselves in harsh arguments in front of their children. Because their harsh arguments affected the mental and physical health of young adults. Earlier experiences of experiencing inter-parental conflict may adversely affect the personality development of young adults later on. However, parents were not included in the study so a detailed profile of inter-parental conflict could not be investigated. Sample was approached just before their final exams so some of the respondents may already be under stress.

\section{RECOMMENDATIONS}

1. Parents should be encouraged to participate in such studies. Some other factors like education and job status of parents should also be considered in connection of their conflicts.

2. Future studies should be conducted on a large sample to increase the generalization of findings.

3. Government should conduct some workshops or seminars at community level to provide awareness to parents about how their conflicts negatively effect their children's mental health.

\section{REFERENCES}

Behar, D., Hunt, J., Ricciuti, A., Stoff, D., \&Vitiello, B. (1990).Sub-typing aggression in children and adolescents. The Journal of Neuropsychiatry and Clinical Neurosciences, 2(2), 189-192.

Bernet, W., Wamboldt, M.Z., \& Narrow, W.E. (2016). Child affected by parental relationship distress. Journal of the American Academy of Child and Adolescent Psychiatry, 55, 571-579.

Buehler, C., Anthony, C., Krishuakumar, A., Stone, G., Gerard, J., \& Pemberton, S. (1997). Interparental conflict and youth problem behaviors: A meta-analysis. Journal of Child and Family Studies, 6, 233-247. 
Buehler, C., Krishnakumar, A., Anthony, C., Tittsworth, S., \& Stone, G. (1997). Hostile interparental conflict and youth maladjustment. Journal of Family Relations, 43, 409-416.

Cummings, E., \& Davies, P. (2002). Effects of marital conflict on children: Recent advances and emerging themes in process-oriented research. Journal of Child Psychology and Psychiatry and Allied Disciplines, 43, 31- 63.

Davis, P. T., \& Cummings, E. M. (1994). Marital conflict and child adjustment: an emotional security hypothesis. Psychological Bulletin, 11(6), 387-411.

Davis, B. T., Hops, H., Alpert, A., \& Sheeber, L. (1998). Child responses to parental conflict and their effect on adjustment: A study of triadic relations. Journal of Family Psychology, 12(2), 163-177.

Davies, P. T., \& Lindsay, L.L. (2004). Interparental conflict and adolescent adjustment: why does gender moderate early adolescent vulnerability? Journal of Family Psychology, 18(1), 160-170.

Franken, R. E. (2002). Human Motivation (5th edi). Aggression, coercive action and anger. Wadsworth, USA.

Fosco, G. M., \& Grych, J. H. (2008). Emotional, cognitive, and family systems mediators of children's adjustment to interparental conflict. Journal of Family Psychology, 22(6), 843-854.

Israel, G. D.(2013). Determining sample size. Retrieved from: https://edis.ifas.ufl.edu/pdffiles/PD/PD00600.pdf

Jamil, F., \& Mubashir, T. (2012). Perceived inter-parental conflict and aggression in adolescents [Abstract]. Psychological Abstracts 2011-2013, Institute of applied psychology, university of the Punjab, Pakistan. Retrieved from: http://pu.edu.pk/images/image/Departments/appsy/Psychological-Abstract-2011-13.pdf

Jenkins, J., Simpson, A., Dunn, J., Rasbash, J., \& O'Connor, T, G. (2005). Mutual influence of marital conflict and children's behavior problems: shared and non-shared family risks. Child Dev, 76(1), 24-39.

Kerig, P. K. (1996). Assessing the links between interparental conflict and child adjustment: The conflicts and problem-solving scales. Journal of Family Psychology, 10, 454-473.

Krishnakumar, A., \& Buehler, C. (2000). Interparental conflict and parenting behaviors: A meta-analytic review. Family Relations, 49(1), 25-44.

Litrownik, A. J., Newton, R., Hunter, W. M., Diana, E., \& Everson, M. D. (2003). Exposure to family violence in young at risk children: A longitudinal look at the effects of victimization and witnessed physical and psychological aggression. Journal of Family Violence, 18(1), 59-73.

Marcus, N. E., Lindahl, K. M., \& Malik, N. M. (2001). Interparental conflict, children's social cognitions, and child aggression: a test of a mediational model. Journal of Family Psychology, 15(2), 315-333.

Mash, E. J. \& Dozois, J. A. (2003). Child psychopathology: A developmental- systems perspective. In E. J. Mash \& R. A. Barkley (Eds.), Child Psychopathology (2nd ed.). New York: Guilford Press.

McDonald, R., \& Grych, J. H. (2006). Young children's appraisals of interparental conflict:

Measurement and links with adjustment problems. Journal of Family Psychology, 20(1), 88-99 
Narayan, A.J., Labella, M.H., Englund, M.M., Carlson, E.A., \& Egeland, B. (2017). The legacy of early childhood vioelnce exposure to adulthood intimate partner violence: Variable- and person-oriented evidence. Journal of Family Psychology, 31, 833- 843.

Nicholas, K. B., \& Elizabeth, H., \& Rasmussen, E. H. (2006). Childhood abusive and supportive experiences, inter-parental violence, and parental alcohol use: prediction of young adult depressive symptoms and aggression. Journal of Family Violence, 21(1), 43-61.

Orpinas, P., Murray, N., \& Kelder, S. (1999). Parental influences on students' aggressive behaviors and weapon carrying. Health Education \& Behavior, 26 (6), 774-787.

Repetti, R. L., Taylor, S. E., \& Seeman, T. E. (2002). Risky families: family social environments and the mental and physical health of offspring. Psychological Bulletin, $128(2), 330-366$. 